invasive alternative procedures. Gerberding also suggested that if a policy had been implemented in 1970 requiring $\mathrm{HBV}$ vaccination for matriculation in professional school, for those already in practice, and for continued contact with patients, more than $95 \%$ of clinician-to-patient transmission of HBV would have been prevented.

FROM: 1. Esteban JI, Gomez J, Martell M, et al. Transmission of hepatitis $\mathrm{C}$ virus by a cardiac surgeon. $N$ Engl J Med 1996;334:555-560.

2. Harpaz R, VonSeidlein L, Averhoff FM, et al. Transmission of hepatitis B virus to multiple patients from a surgeon without evidence of inadequate infection control. N Engl J Med 1996;334:549-554.

3. Gerberding JL. The infected healthcare provider. $N$ Engl J Med 1996;334:594-595.

\section{Mad Cows and CJD}

The British Government recently announced that there may be a link between bovine spongiform encephalopathy and Creutzfeldt-Jakob Disease (CJD). A committee of scientists set up to advise the government on this issue concluded that the recent outbreak of CJD was linked to the fatal neurologic disease of cattle known as "mad cow disease." A doubling in reported cases of CJD occurred between 1990 and 1994, reaching 55 cases in 1994. Ten cases were discovered in individuals under the age of 41, with some in their teens; normally, CJD affects an older age group. In addition, four dairy farmers whose herds had become infected with mad cow disease developed CJD. The incidence of mad cow disease in Britain has been decreasing after reaching a peak of 900 to 1,000 cases per week in 1992 and 1993. There were approximately 200 to 300 cases per week in January 1996. Experts estimate that more than 1 million infected animals have been consumed already.

CJD is a rare disease affecting one per million people. The incubation period is between 10 and 40 years. CJD was thought to be related to bovine spongiform encephalopathy because the two diseases have similar pathology and clinical course. The precise cause of CJD is still a mystery; earlier theories have suggested a virus-like agent, but recent research has advanced a theory that relates both diseases to an abnormal protein in the cell membrane, presumably transmitted through exposure or consumption of infected tissue, which sets off a chain reaction that damages other proteins.

One theory of why it has appeared in British cows is that bovine encephalopathy can be traced to a similar disease in sheep, scrapie, that may have crossed the species barrier in Britain. Experts note that this theory is supported by the practice for years of taking bone and meat remnants from sheep, including brains, grinding it up, and feeding it to cows as a protein supplement. This practice recently was stopped, however.

British Health Secretary Steven Dorrell said it was believed that the 10 new cases of CJD had acquired their disease from exposure to bovine spongiform encephalopathy before 1989. In that year, measures were adopted for abattoirs to dispose of specified offal from cows, including the brains, by burning them. But spot inspections show that the regulations are not always observed. The US Department of Agriculture said that no processed beef or cattle have been imported into the United States from Britain since 1989 and that mad cow disease has not been detected in this country.

FROM: Darnton J. Britain ties deadly brain disease to cow ailment. New York Times March 21, 1996;Al.

\section{Infectious Diseases Mortality Rises}

The CDC reported recently that the US death rate due to infectious diseases as the underlying cause of death increased 55\% from 1980 to 1992, from 41 to 65 deaths per 100,000 population. Age-adjusted mortality from infectious diseases increased 39\% during the same period. Infectious diseases mortality increased 25\% among those aged 65 years and older and 6.3 times among 25 to 44 year olds. Considered together, infectious diseases were the third leading cause of death in the United States in 1992.

The authors point out that information about infectious diseases usually is presented one disease at a time, causing a fragmented overall view of infectious diseases by obscuring their aggregate impact. This approach can confound public policy decisions, which rest on assessment of infectious disease in the context of other public health or policy issues and may be based more on current estimates than trends. Infectious disease trends are susceptible to rapid shifts, in contrast to other disease categories such as cancer and heart disease. Thus, to anticipate public health threats effectively, these trends must be monitored as well, and policy decisions must take them into account.

The authors note that public health policy during the past 2 decades has been based largely on trends in the earlier part of this century, when mortality from infectious diseases was declining. However, the thesis that infectious diseases would continue to decrease in the United States and other developed countries and be replaced in time by noninfectious causes of death requires reconsideration.

The Institute of Medicine recently provided a conceptual framework for this issue in their report on emerging infections by characterizing the dynamic factors that allow or promote the emergence and reemergence of infectious disease. These include increasing population size and age, changes in human behaviors, and rapid changes in technology and industry, creating new niches for microbial pathogens. These trends call for renewed interest in infectious diseases in the medical and public health communities.

The authors conclude that, despite historical predictions that infectious diseases would wane in the United States, these data show that infectious disease mortality in the United States has been increasing in recent years. This study was reported in the January 17, 1996, issue of the Journal of the American Medical Association (JAMA) as part of a series of articles on emerging infections. In January, JAMA joined 35 other medical journals worldwide to document the occurrence, causes, and consequences of emerging and reemerging infections. This resurgence of 
scientific interest has been matched in popular media, news magazines, newspaper headlines, television shows, best-selling books, and movies such as Outbreak. (See related Medical News story on emerging infections.)

FROM: Pinner RW, Teutsch SM, Simonsen L, et. al. Trends in infectious disease mortality in the United States. JAMA 1996;275:189-193.

\section{Journals Feature Emerging Infections}

Thirty-six journals in 21 countries agreed to devote all or part of one of their issues to the subject of emerging and reemerging global microbial threats. This international collaboration will publish more than 200 articles. ${ }^{1}$ The first-ever global theme issue of medical journals was coordinated by three editors, Linda Hawes Clever, of the Western Journal of Medicine, Magne Nylenna, MD, editor of the Journal of the Norwegian Medical Association, and George D. Lundberg, MD, editor of the Journal of the American Medical Association (JAMA). Research on tuberculosis, toxigenic Escherichia coli, drug-resistant pneumococcal pneumonia, hepatitis $\mathrm{B}$ and $\mathrm{C}$, cholera, and AIDS will be presented to the readers of journals from Buenos Aires to Syndey to Johannesburg to Beijing. Hantavirus infection is identified in Argentina, Bolivia, and Uruguay, and cat-scratch fever is reviewed in the Netherlands.

Some of the articles offer hope, shedding light on successes and renewed efforts at combating infectious disease. In Iceland, for example, decline in the use of antimicrobials attributable to public education and legislation has been followed by reduced rates of resistant streptococcal pneumonia, and, in the Americas, the Pan American Health Organization has led efforts to eliminate measles from the Western Hemisphere.

An editorial in the January 17,1996 , issue of $J A M A$ by Joshua Lederberg, chair of the Institute of Medicine's Committee on Emerging Infections, notes the importance of this attention to the issue of emerging infections, to reinforce and clarify our consensual medical scientific perspectives, and the "reinforcement they give to the public explicators of contingencies, and [to] government. ${ }^{2}$

"Citations for all articles to be published in the 36 journals are available through the JAMA home page of the American Medical Association's World Wide Web site: http//www.ama-assn.org.

FROM: 1. Winker MA, Flanagin A. Infectious disease: a global approach to a global problem. JAMA 1996;275(3):245-246.

2. Lederberg J. Infection emergent. JAMA 1996;275(3): 243-244.

\section{Terrorist Access to Biologic Agents}

Federal health officials are concerned over a national tissue association's release of a stock culture of Yersinia pestis (plague Bacillus) to a private citizen in Ohio who purported to be a member of the American Society of Microbiology.
In recent testimony given before a US Senate Judiciary Committee, Dr. James Hughes, Director of CDC's National Center for Infectious Disease, testified that "there are a number of federal regulations that address the shipping and handling of infectious agents, however, they are not completely effective at controlling possession and transfer of human infectious agents." Hughes pointed out that, even though there may be up to a few thousand interstate transfers of dangerous human infectious agents for legitimate scientific research, the Ohio incident was the only incident of inappropriate transfer that has ever been reported. Dr. Hughes said, "the goal is to strike a balance between assuring the availability of infectious and recombinant DNA materials to the scientific and medical community for important public health and biotechnical research and preventing access to these agents for other than legitimate scientific and medical purposes.”

Dr. David Satcher, CDC's director, recently sent a letter to the presidents of a number of associations and groups whose members work with pathogenic agents. He pointed out that the CDC was very concerned about the threat of terrorist activity involving the use of biologic agents and the illicit use and interstate transport of certain human pathogenic agents. He requested that organizations and professional microbiologists who authorize the acquisition and transfer of dangerous human infectious agents increase their vigilance to minimize the risk of illicit access to these agents. Requests for agents that cause anthrax, botulism, brucellosis, plague, Q-fever, tularemia, and any agent classified for work at Biosafety Level 4 (ie, Ebola and most other hemorrhagic viruses) should be reviewed to determine if they are being used for legitimate medical or scientific purposes. Suspicious inquiries or transactions should be reported to CDC's Office of Health and Safety (404-639-3235).

CDC co-chairs a federal interdepartmental working group that is developing regulations regarding the acquisition and transfer of certain biologic agents. These regulations will be developed with input from professional organizations, the research community, and law enforcement authorities. A notice of proposed rulemaking will be published in the Federal Register. In addition, the Department of Justice is working to strengthen relevant criminal statutes to enable prosecution of those who attempt to gain illicit access to these biologic agents.

FROM: 1. Satcher D. Letter to professional associations that handle pathogenic agents. March 12, 1996.

2. Testimony by James Hughes, MD, before the US Senate Judiciary Committee, March 6, 1996.

\section{OSHA Revises TB Enforcement}

On February 9, 1996, OSHA issued "Enforcement Procedures and Scheduling for Occupational Exposure to Tuberculosis" (OSHA Instruction CPL 2.106). This compliance directive provides for uniform procedures and guidelines to be followed when conducting inspections and issuing citations in the absence of a TB standard.

The compliance directive focuses on the primary control measures that are outlined in the CDC guidelines: early 